\title{
Neuroblastoma cells depend on HDAC11 for mitotic cell cycle progression and survival
}

\author{
Theresa M Thole ${ }^{1,2,3}$, Marco Lodrini ${ }^{1,3}$, Johannes Fabian ${ }^{3,11}$, Jasmin Wuenschel ${ }^{1,3}$, Sebastian Pfeil ${ }^{1}$, Thomas Hielscher ${ }^{4}$, \\ Annette Kopp-Schneider ${ }^{4}$, Ulrike Heinicke ${ }^{5}$, Simone Fulda ${ }^{5,6,7}$, Olaf Witt ${ }^{2,3}$, Angelika Eggert ${ }^{1}$, Matthias Fischer ${ }^{8,9}$ and \\ Hedwig E Deubzer ${ }^{*, 1,2,3,10}$
}

The number of long-term survivors of high-risk neuroblastoma remains discouraging, with 10 -year survival as low as $20 \%$, despite decades of considerable international efforts to improve outcome. Major obstacles remain and include managing resistance to induction therapy, which causes tumor progression and early death in high-risk patients, and managing chemotherapy-resistant relapses, which can occur years after the initial diagnosis. Identifying and validating novel therapeutic targets is essential to improve treatment. Delineating and deciphering specific functions of single histone deacetylases in neuroblastoma may support development of targeted acetylome-modifying therapeutics for patients with molecularly defined high-risk neuroblastoma profiles. We show here that HDAC11 depletion in MYCN-driven neuroblastoma cell lines strongly induces cell death, mostly mediated by apoptotic programs. Genes necessary for mitotic cell cycle progression and cell division were most prominently enriched in at least two of three time points in whole-genome expression data combined from two cell systems, and all nine genes in these functional categories were strongly repressed, including CENPA, KIF14, KIF23 and RACGAP1. Enforced expression of one selected candidate, RACGAP1, partially rescued the induction of apoptosis caused by HDAC11 depletion. High-level expression of all nine genes in primary neuroblastomas significantly correlated with unfavorable overall and event-free survival in patients, suggesting a role in mediating the more aggressive biological and clinical phenotype of these tumors. Our study identified a group of cell cyclepromoting genes regulated by HDAC11, being both predictors of unfavorable patient outcome and essential for tumor cell viability. The data indicate a significant role of HDAC11 for mitotic cell cycle progression and survival of MYCN-amplified neuroblastoma cells, and suggests that HDAC11 could be a valuable drug target.

Cell Death and Disease (2017) 8, e2635; doi:10.1038/cddis.2017.49; published online 2 March 2017

Neuroblastoma, a neuroectodermally derived embryonic tumor and most common extracranial tumor of childhood, remains a major cause of cancer-related deaths in children, mostly due to systemic and resistant relapses. ${ }^{1} \mathrm{MYCN}$ oncogene amplifications, ${ }^{2,3}$ TERT activation by genomic rearrangements, ${ }^{4,5} A T R X$ loss-of-function mutations/deletions ${ }^{6}$ and germline/somatic activating $A L K$ mutations $^{7-10}$ define patient subgroups at high risk for failing primary long-term remission despite aggressive multimodal treatment. Treatment for relapsed neuroblastoma and even first-line therapy for molecularly defined high-risk disease is currently undergoing a paradigm shift from classical cytotoxic agent combinations toward incorporating targeted drugs and immunotherapeutics into treatment schedules. Developing how and when to combine these newer precise therapeutics with established treatment elements such as classical chemotherapy is challenging.

Drugs currently under clinical investigation for relapsed/ refractory neuroblastoma patients include the mTOR inhibitor, rapamycin (NCT01467986), and the ALK inhibitors, crizotinib (NCT00939770, NCT02559778, NCT01606878, NCT02034981) and LDK378 (NCT01742286). The strong anti-tumoral activities of inhibitors for HDAC family members, AURKA, BET/bromodomain-containing proteins, MDM2, MAP2K1 (formerly MEK) and CDK4/6 observed in preclinical neuroblastoma models ${ }^{11-16}$ suggest that further drugs will enter pediatric phase I testing in the near future. Inhibitors of class I or all classical histone deacetylases that are currently approved or being evaluated in clinical cancer trials in adults ${ }^{17}$ give rise to mostly hematological dose-limiting toxicities,

\footnotetext{
${ }^{1}$ Department of Pediatric Hematology, Oncology and SCT, Charité-Universitätsmedizin Berlin, Campus Virchow-Klinikum, Augustenburger Platz 1, Berlin 13353, Germany; ${ }^{2}$ Department of Pediatric Hematology and Oncology, University of Heidelberg, INF 430, Heidelberg 69120, Germany; ${ }^{3}$ Clinical Cooperation Unit Pediatric Oncology, German Cancer Research Center (DKFZ) and German Consortium for Translational Cancer Research (DKTK), INF 280, Heidelberg 69120, Germany; ${ }^{4}$ Department of Biostatistics, German Cancer Research Center (DKFZ), INF581, Heidelberg 69120, Germany; ${ }^{5}$ Institute for Experimental Cancer Research in Pediatrics, J. W. Goethe University Hospital Frankfurt, Korntur Str. 3a, Frankfurt am Main 60528, Germany; ${ }^{6}$ German Cancer Consortium (DKTK), INF 280, Heidelberg 69120, Germany; ${ }^{7}$ German Cancer Research Center (DKFZ), INF 280, Heidelberg 69120, Germany; ${ }^{8}$ Department of Pediatric Hematology and Oncology, University of Cologne, Kerpener Str. 62, Cologne 50937, Germany; ${ }^{9}$ Department of Children and Adolescent Medicine, Center for Molecular Medicine Cologne, University of Cologne, Robert-Koch-Str. 21, Cologne 50931, Germany and ${ }^{10}$ Junior Neuroblastoma Research Group, Experimental and Clinical Research Center (ECRC) of the Max-Delbrück Center for Molecular Medicine (MDC) in the Helmholtz Community and the Charité-University Medicine Berlin, Lindenberger Weg 80, Berlin 13125, Germany

${ }^{*}$ Corresponding author: HE Deubzer, Department of Pediatric Hematology, Oncology and SCT, Charité-Universitätsmedizin Berlin, Campus Virchow-Klinikum, Augustenburger Platz 1, Berlin 13353, Germany. Tel: +49 30 450616157; Fax: +49 30 4507516925; E-mail: hedwig.deubzer@charite.de

${ }^{11}$ Current address: Phenex Pharmaceuticals AG, Waldhofer Straße 104, Heidelberg 69123, Germany.

Received 01.8.16; revised 01.12.16; accepted 25.1.17; Edited by A Verkhratsky
} 


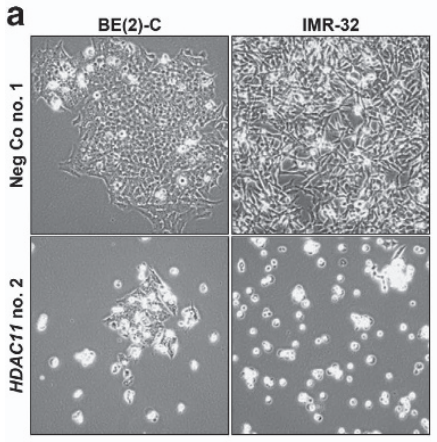

C

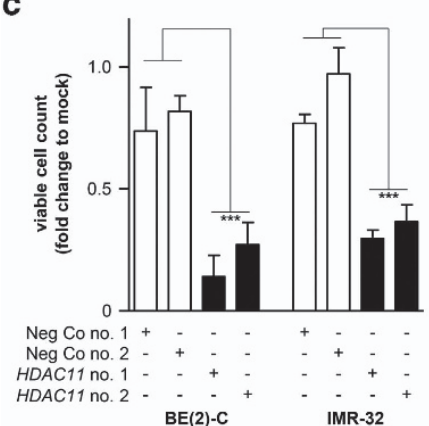

b

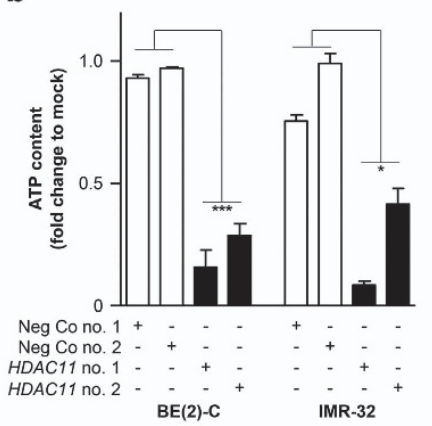

d

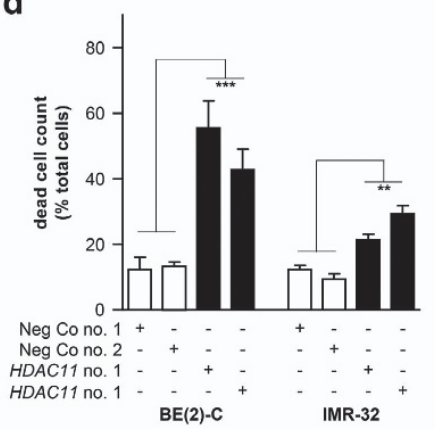

e

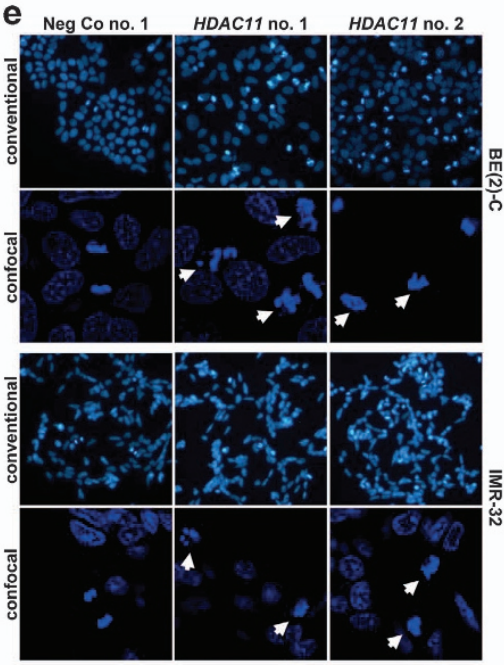

f

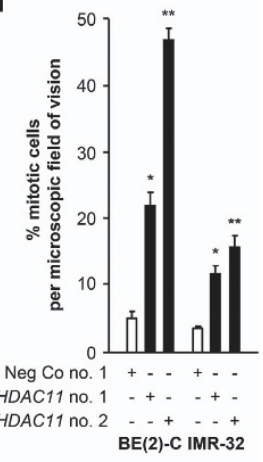

Figure 1 HDAC11 depletion in neuroblastoma cells causes aberrant mitosis and cell death. (a) Phase contrast microscopy pictures showing the phenotype of $\mathrm{BE}(2)-\mathrm{C}$ and IMR-32 neuroblastoma cells $96 \mathrm{~h}$ after transfection with HDAC11- or negative control siRNA. Original magnification $\times 200$. (b) Intracellular ATP content of BE(2)-C and IMR-32 cultures $96 \mathrm{~h}$ after transfection with HDAC11- or negative control siRNAs (mean fold change over mock-transfected cells \pm S.D. is shown, $n=3$ ). (c and d) Viable and dead BE (2)-C and IMR-32 cell count using a semi-automatic VI-CELL Cell Viability Analyzer $96 \mathrm{~h}$ after transfection with HDAC11- or negative control siRNAs. Mean fold change over viable mock-transfected cells \pm S.D. is shown in (c), $n \geqslant 3$. Mean percentage of dead cells is shown in $\mathbf{d}, n \geqslant 3$. (e) Fluorescent microscopic and confocal images of DAPI-stained DNA in BE(2)-C and IMR-32 cells transfected with HDAC11- or negative control siRNA for $48 \mathrm{~h}$. DAPI-stained cells were analyzed using the $\times 20$ objective on a conventional widefield microscope and the $\times 63$ objective on a confocal microscope. Arrowheads indicate aberrantly constituted mitotic spindle assemblies. (f) Quantification of the fluorescent microscopic images shown in e. At least 10 microscopic fields were evaluated per treatment group by two experimenters. (g) Western blot analysis of phospho Histone $\mathrm{H} 3$ (Ser10) expression $48 \mathrm{~h}$ after transfection of $H D A C 11$ - or negative control siRNA. Histone $\mathrm{H} 3$ served as loading control. ${ }^{\star} P<0.05 ;{ }^{* \star} P \leqslant 0.01 ;{ }^{* \star *} P \leqslant 0.001$

presumably due to the inhibition of several family members. This could potentially be overcome by selective blockade of single HDAC family members.

Further advances in understanding the role of single histone deacetylases are a prerequisite to fully exploiting the level of plasticity that can be therapeutically addressed with this class of acetylome-modifying drugs. MYCN was shown to recruit HDAC1/2/3/5 to promoter sites to repress transcription in neuroblastoma cells, ${ }^{18-21}$ whereas HDAC8 and HDAC10 inhibit differentiation and promote autophagy-mediated survival in a MYCN-independent manner. ${ }^{22,23}$ Gao et al. ${ }^{24}$ identified and characterized HDAC11 in 2002, the only class IV HDAC family member identified to date, which is located within the $\sim 25 \mathrm{~kb}$ region of chromosome 3p25.1. Expression of the FLAG-tagged 347 amino acid open reading frame in human embryonic kidney 293 cells, demonstrated the protein primarily localizes to the nucleus and is capable of deacetylating a synthetic peptide derived from histone $\mathrm{H} 4 .{ }^{24}$ Subsequent studies in recent years have shed light on the role of HDAC11 in health and disease. ${ }^{25}$ Here we aimed to assess the significance of HDAC11 expression for neuroblastoma biology, which is as yet unknown. We recently showed that HDAC11 plays an important role in controlling proliferation in several carcinoma cell lines. ${ }^{26} \mathrm{BE}(2)$ $\mathrm{C}$ and IMR-32 were chosen as representative cell lines for the high-risk neuroblastoma subtype characterized by $M Y C N$ amplification and loss of heterozygosity at chromosome $1 \mathrm{p}$. The BE(2)-C cell line, established from a bone marrow metastasis after the patient had received 5 months of polychemotherapy, ${ }^{27}$ is hemizygous for TP53, with the remaining allele harboring a missense mutation at codon 135 that renders TP53 non-function and the cell line resistance to doxorubicin. ${ }^{28}$ IMR-32 cells harbor a partial ALK amplification, resulting in constitutive ALK activity leading to uncontrolled proliferation. ${ }^{29}$ We assessed the effect of HDAC11 depletion on phenotype in these two neuroblastoma cell models and performed whole-genome expression profiling to decipher the pathways triggering the HDAC11 depletion phenotype in neuroblastoma cells.

\section{Results}

HDAC11 depletion in neuroblastoma cells triggers cell death preceded by aberrant mitotic spindle assemblies. To decipher mechanisms controlled by HDAC11 in neuroblastoma cells, we assessed phenotypic appearance, intracellular adenosine triphosphate (ATP) content, and number of viable and dead cells following transient HDAC11 knockdown in BE(2)-C and IMR-32 cells. Two different siRNAs directed against HDAC11 (Supplementary Table S1) were used to 
control unspecific and off-target effects. HDAC11 expression was reduced up to $95 \%$ on the mRNA level, as measured by qRT-PCR (Supplementary Table S2; Supplementary Figures $\mathrm{S} 1 \mathrm{a}-\mathrm{b})$, and up to $85 \%$ on the protein level related by western blotting (Supplementary Figures S1c-d). Cell culture density was reduced by HDAC11 depletion, and detached single cells and clusters floated in the culture medium $96 \mathrm{~h}$ after transfection (Figure 1a), suggesting proliferative inhibition and cell death induction. Intracellular ATP content was quantified $96 \mathrm{~h}$ after transfection by the CellTiter-Glo assay. HDAC11 depletion diminished ATP content in BE(2)-C and IMR-32 cells by 59-93\%, compared to cells transfected with negative controls (Figure 1b), indicating that loss of HDAC11 activity reduced metabolic activity. Consistent with this finding, semi-automated cell viability analysis based on trypan blue exclusion revealed a $63-86 \%$ reduction in the number of membrane-intact viable $\mathrm{BE}(2)-\mathrm{C}$ or IMR-32 cells $96 \mathrm{~h}$ after HDAC11 depletion (Figure 1c), whereas the number of membrane-permeable dead cells increased by 1.8- to 4.5-fold (Figure 1d). Transient HDAC11 knockdown in the SH-SY5Y and SK-N-AS neuroblastoma cell lines, which lack MYCN amplification, diminished ATP content by 21-38\% (Supplementary Figures S2a-b). Semi-automated analyses detected a $32-45 \%$ reduction in the number of viable SH-SY5Y or SK-N-AS cells $96 \mathrm{~h}$ after HDAC11 depletion and a 1.3- to 1.7-fold increase in the number of dead cells (Supplementary Figures S2c-d). We observed an apparent increase in mitotic $B E(2)-C$ and IMR-32 cells using fluorescent microscopy of diamidino-2-phenylindole (DAPI)stained adherently growing cells $48 \mathrm{~h}$ after HDAC11 depletion and prior to time points assessing cell death (Figure 1e). Quantifying the percentage of mitotic cells per microscopic field showed HDAC11 depletion increased mitotic BE(2)-C cells from $5 \%$ to $22-47 \%$ and mitotic IMR-32 cells from $4 \%$ to $12-16 \%$ (Figure 1f). Confocal microscopy of the DAPIstained cells revealed aberrantly constituted mitotic spindle assemblies in HDAC11-depleted cells while negative controls harbored normal appearing mitotic spindle assemblies (Figure 1e). Ser10 of histone $\mathrm{H} 3$ is phosphorylated in mitotic cells, allowing direct quantification of mitotic cells. HDAC11 depletion increased phospho H3 (Ser10) levels by approximately three-fold in $B E(2)-C$ and IMR-32 cells $48 \mathrm{~h}$ after

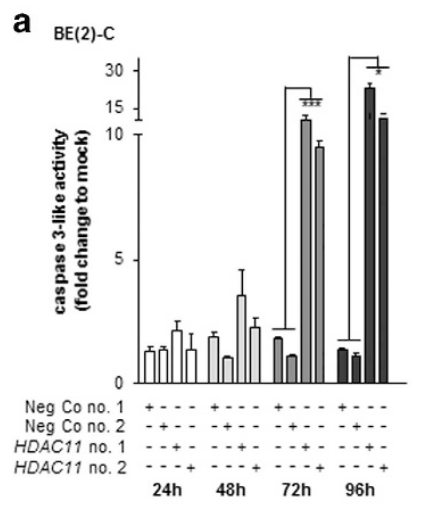

e

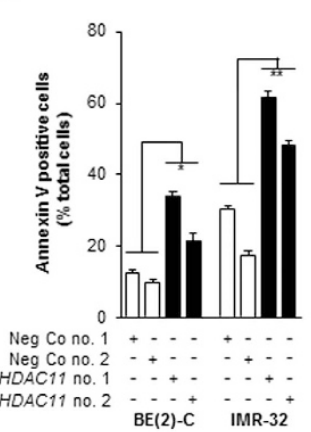

b

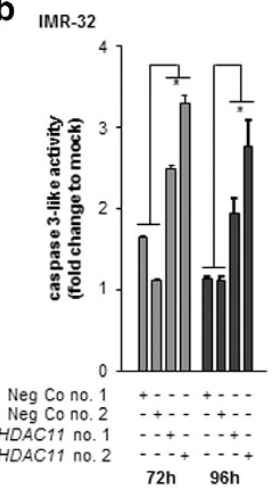

C $B E(2)-C$

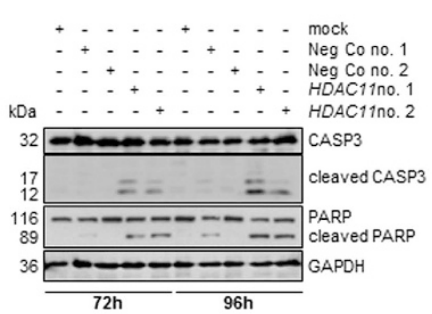

d ${ }_{1 M R-32}$

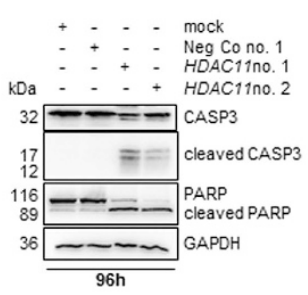

f

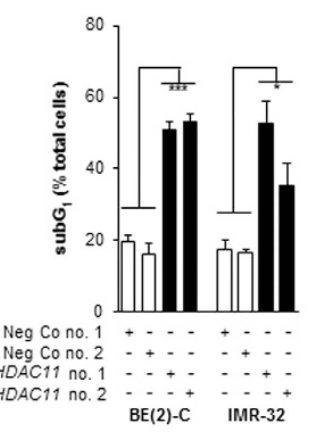

g

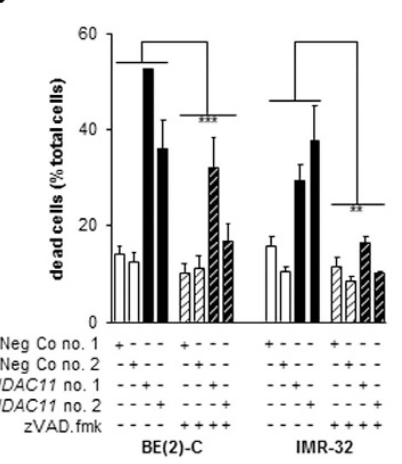

h $B E(2)-C$

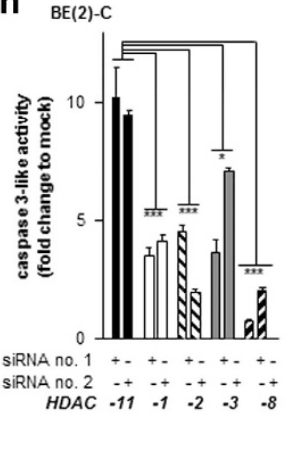

i 1 IMR32

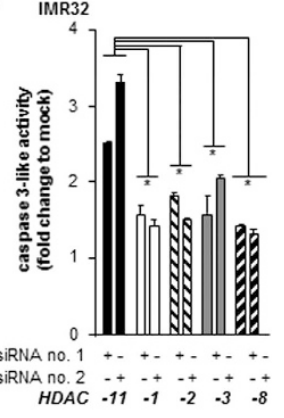

Figure 2 HDAC11 depletion in neuroblastoma cells triggers caspase activation and caspase-dependent apoptosis. (a and $\mathbf{b}$ ) Caspase 3-like activity was measured in a caspase 3-like activity assay in time course 24-96 h after transfection of BE(2)-C and 72-96 h after transfection of IMR-32 cells with HDAC11- or negative control siRNAs (mean fold changes over mock \pm S.D., $n=3$ ). (c and d) CASP3 and PARP cleavage was analyzed by western blotting $72-96 \mathrm{~h}$ after transfection of $\mathrm{BE}(2)-\mathrm{C}(\mathbf{c})$ and IMR-32 cells (d) with HDAC11- or negative control siRNAs. Shown are the full-length CASP3 (32 kDa) and poly (ADP-ribose) polymerase (PARP) proteins (116 kDa), and the active cleavage bands of CASP3 $(17,12 \mathrm{kDa}$ ) and PARP (89 kDa). GAPDH served as a loading control. (e and f) Early- and late-stage apoptosis was determined by staining of annexin V shifted to the outer plasma membrane $72 \mathrm{~h}$ after siRNA transfection (e; mean \pm S.D., $n \geqslant 5$ ) and by quantifying DNA fragmentation in propidium iodide-stained nuclei at $96 \mathrm{~h}$ (f; mean \pm S.D., $n=3)$. (g) BE(2)-C and IMR-32 cells were transfected with HDAC11- or negative control siRNAs and treated with $20 \mu \mathrm{M} \mathrm{zVAD}$.fmk or solvent control for $96 \mathrm{~h}$. Shown is the mean percentage of dead cells \pm S.D. measured with a semi-automated VI-CELL Cell Viability Analyzer $(n \geqslant 3)$. ( $h$ and i) Comparison of caspase 3 -like activity in BE(2)-C (h) and IMR-32 cells (i) transfected for $72 \mathrm{~h}$ with HDAC11 siRNAs or siRNAs directed against the class I HDACs 1, 2, 3 or 8 (mean fold change over mock \pm S.D., $n=3$ ). ${ }^{*} P<0.05$; ${ }^{* \star} P \leqslant 0.01 ;{ }^{* \star \star} P \leqslant 0.001$ 
siRNA transfection (Figure 1g), supporting the increase in mitotic cells observed microscopically. Fluorescenceactivated cell sorting (FACS) of propidium iodide-stained BE (2)-C cells demonstrated an increase of cells in G2/M from 33 to $51 \% 48 \mathrm{~h}$ after HDAC11 depletion (Supplementary Figures S3a-e). Our results in neuroblastoma cell lines with and without MYCN amplifications collectively highlight the significance of HDAC11 expression for cellular viability, particularly in the presence of $M Y C N$ amplification. Taken together, our experiments show that HDAC11 depletion in neuroblastoma cells causes formation of aberrant mitotic spindle assemblies followed by increased cell death.

HDAC11 depletion in neuroblastoma cells induces apoptosis. To test whether apoptosis was involved in the phenotype observed, we conducted caspase 3-like activity assays, PARP western blotting, quantification of cell surface phosphatidylserine expression and DNA fragmentation by FACS. The time-response kinetic investigating caspase 3-like activity 24-96 $\mathrm{h}$ after siRNA transfection in BE(2)-C cells demonstrated that HDAC11 depletion elicited an $\sim 10$ fold increase in caspase 3-like activity over negative controls at $72 \mathrm{~h}$, reaching 11- to 23-fold at $96 \mathrm{~h}$ (Figure 2a). Caspase 3-like activity in IMR-32 was elevated up to 3.5-fold above negative controls (Figure $2 b$ ). Caspase 3 cleavage fragments were detected in $B E(2)-C$ and IMR-32 cells by western blotting (Figures 2c and d). Caspase-mediated apoptosis involves cleavage of numerous substrates including PARP1, a nuclear enzyme involved in DNA repair. Western blotting detected increased cleavage to the 89-kDa PARP1 fragment 72 and $96 \mathrm{~h}$ after HDAC11 depletion (Figures 2c and d). To collect further evidence that HDAC11 depletion induces apoptosis, we analyzed the shift of phosphatidylserine from the inner to the outer plasma membrane leaflet during apoptosis using annexin V staining. Outer surface localization of phosphatidylserine increased by 1.6- to 3.5-fold in $B E(2)-C$ and IMR-32 cells $72 \mathrm{~h}$ after siRNA transfection for HDAC11 depletion (Figure 2e; Supplementary Figure S4a). The percentage of cells with fragmented DNA (sub-G1 fraction) was determined by FACS analysis of propidium iodidestained cells. HDAC11 depletion triggered a 2- to 3.2-fold increase in sub-G1 BE(2)-C and IMR-32 cells, reaching up to $62 \% 96 \mathrm{~h}$ after transfection (Figure 2f; Supplementary Figure S4b). To assess the contribution of apoptosis to the phenotype mediated by HDAC11 depletion, we combined treatment with the pan-caspase inhibitor, zVAD.fmk, with transfection of HDAC11-directed or negative control siRNA, then quantified the number of dead BE(2)-C and IMR-32 cells by semi-automated trypan blue staining. Stable inhibition of proteolysis by activated caspases substantially prevented cell death induction by HDAC11 depletion in BE(2)-C and IMR-32 cells (Figure $2 \mathrm{~g}$ ). The dependence of cell death induction on caspase activity, the confirmation of PARP1 cleavage, the increased cell surface localization of phosphatidylserine and the presence of DNA fragmentation in dead or dying cells strongly support a major involvement of the apoptotic machinery in the phenotype observed.

We compared the induction of caspase 3-like activity by HDAC11 depletion in BE(2)-C cells with that achieved by singly depleting HDAC1, HDAC2, HDAC3 or HDAC8
(Supplementary Figures 1e-h). While HDAC11 depletion resulted in an $\sim 10$-fold increase in caspase 3 -like activity $72 \mathrm{~h}$ after transfection (compare Figure $2 \mathrm{a}$ with Figure $2 \mathrm{~h}$ ), caspase 3-like activity in $\mathrm{BE}(2)-\mathrm{C}$ cells depleted for HDAC1, HDAC2 or HDAC8 was below five-fold of the respective controls and below 7.5-fold of controls for HDAC3-depleted cells (Figure 2h). Likewise, HDAC11 depletion induced caspase 3 -like activity in IMR-32 cells more strongly than singly depleting HDAC1, HDAC2, HDAC3 or HDAC8 (Figure $2 \mathrm{i}$ ). The strength of induction of caspase 3-like activity by HDAC11 depletion suggests that HDAC11 could be a valuable drug target for selective inhibition in concert with other targeted therapeutics.

HDAC11 influences genes involved in mitotic cell cycle progression and cell division. To detect transcriptomic changes by HDAC11 depletion in a time-resolved manner, whole-genome expression profiles of $\mathrm{BE}(2)-\mathrm{C}$ and IMR-32 cells were generated using Illumina Human Sentrix-12 BeadChip arrays 42,48 and $54 \mathrm{~h}$ after transfection with the two different siRNAs targeting HDAC11 or a negative control (compare with Figures 1,2). In total, 259 genes were regulated (120 up and 139 down) by HDAC11 depletion in $\mathrm{BE}(2)-\mathrm{C}$, and 167 genes were regulated (57 up and 110 down) by HDAC11 depletion in IMR-32 cells (Supplementary Information). Genes differentially expressed relative to controls at two or more time points in both cell lines $(P<0.05)$ after HDAC11 depletion were included in gene ontology (GO) analyses. This approach identified 20 enriched biological process terms in BE(2)-C cells and 18 in IMR-32 cells, of which six overlapped in both cell models (Figure 3 ). Biological processes enriched in both cell lines included M-phase of

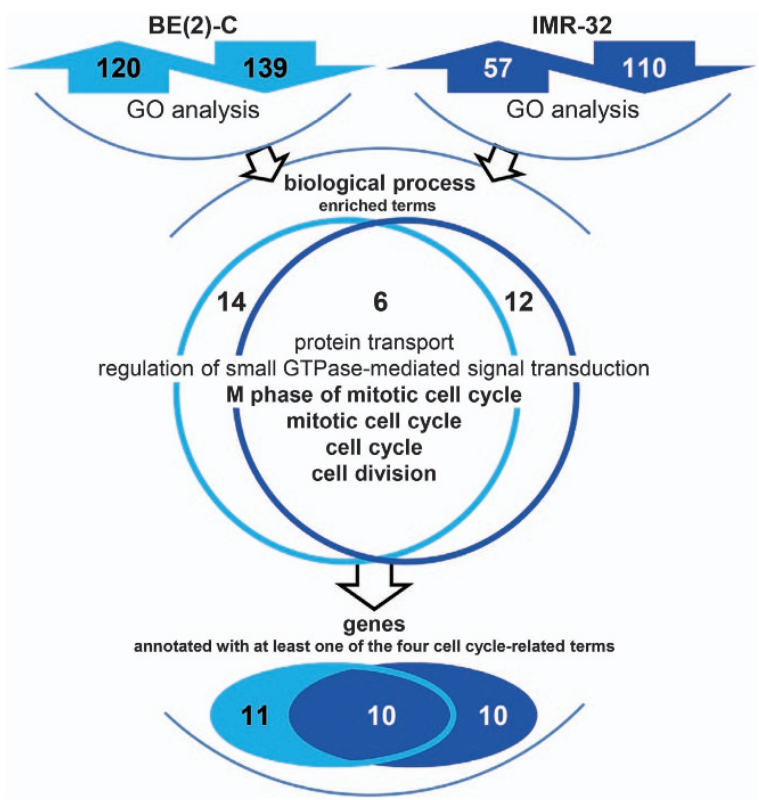

Figure 3 Schematic model showing an enrichment of biological function terms associated with cell cycle and cell division in a $\mathrm{GO}$ analysis of whole-genome gene expression data obtained in time course $(42,48,54 \mathrm{~h})$ from the $\mathrm{BE}(2)-\mathrm{C}$ and IMR-32 cell systems transfected with negative control siRNA or two different HDAC11specific siRNAs 
a Illumina Human Sentrix $x^{\oplus}-12$ BeadChip array

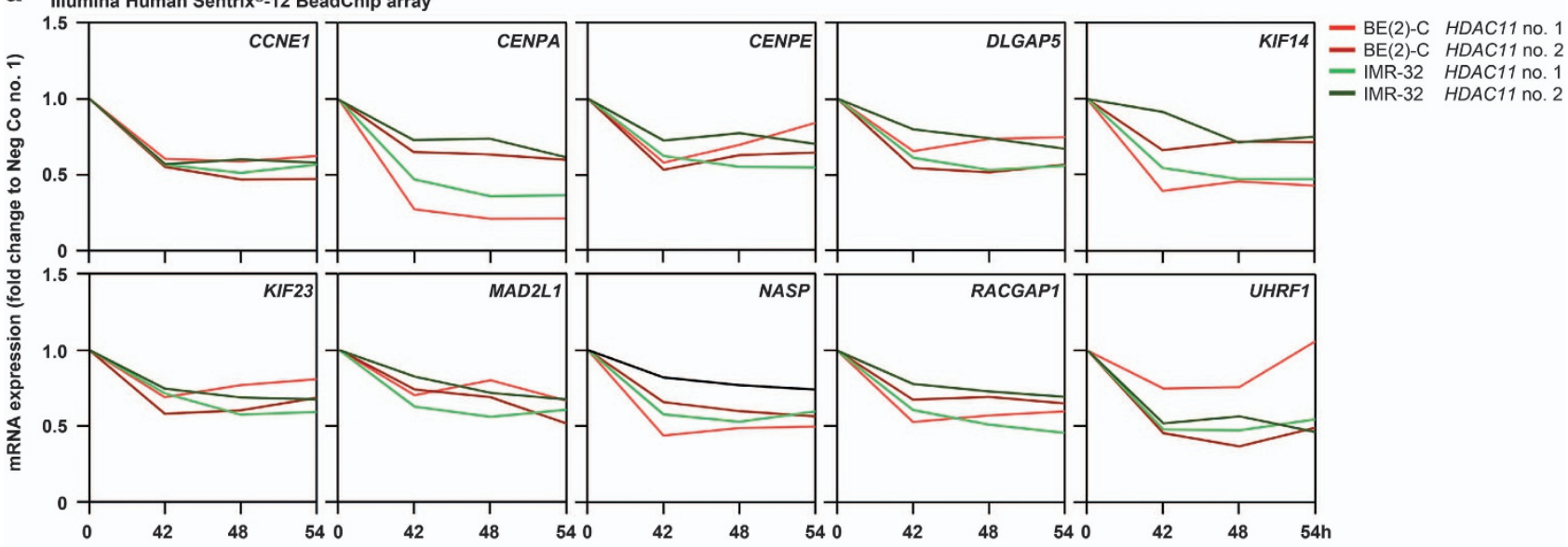

b qRT-PCR 48h

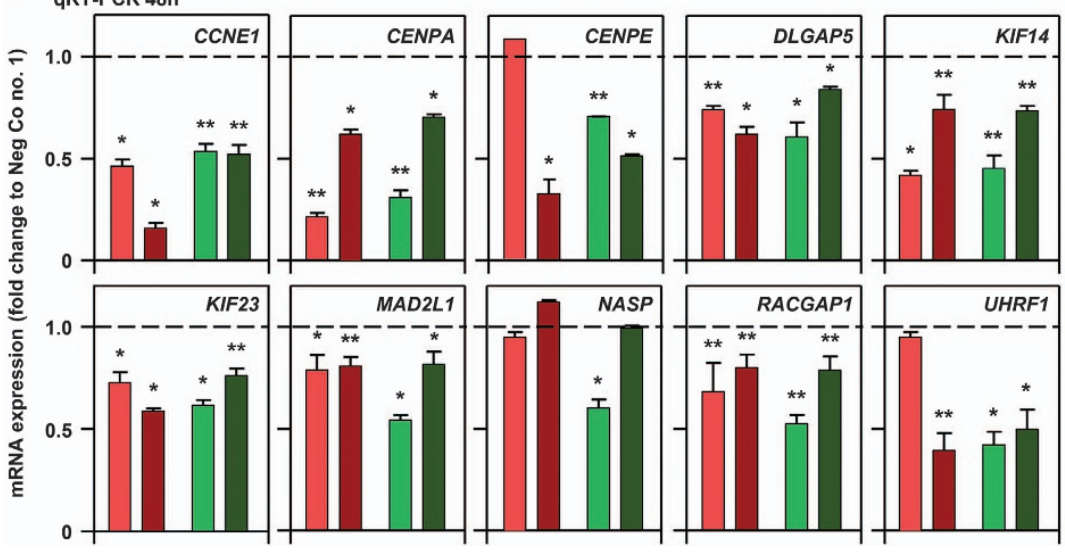

Figure 4 Expression of a group of genes related to the cell cycle and cell division following HDAC11 depletion in neuroblastoma cells. (a) Time course of mRNA expression of differentially regulated genes associated with the $\mathrm{GO}$ terms M-phase of mitotic cell cycle, mitotic cell cycle, cell cycle or cell division. BE(2)-C and IMR-32 cells were transfected with negative control siRNA or two different HDAC11-specific siRNAs for whole-genome expression analysis $(42,48,54 \mathrm{~h}, n=2)$ Mean fold change over negative control siRNA is shown. (b) Validation experiments using qRT-PCR are shown for the $48 \mathrm{~h}$ time point (mean fold change over negative control siRNA \pm S.D., $n \geqslant 3$ ). ${ }^{\star} P<0.05 ;{ }^{* *} P \leqslant 0.01$

mitotic cell cycle, mitotic cell cycle, cell cycle, cell division, protein transport and small GTPase-mediated signal transduction. Finding four biological function terms related to cell cycle and mitosis in the unbiased analysis of expression in time course from both cell lines coupled with our detecting cells accumulating in mitosis then undergoing apoptosis following HDAC11 depletion prompted us to focus on genes related to the terms, cell cycle and mitosis. In total, 21 and 20 genes representing these terms were regulated in $B E(2)-C$ and IMR-32 cells, respectively (Figure 3), with 10 genes being regulated in both cell lines (Figures 3,4a). Downregulation was confirmed for 9 (CCNE1, CENPA, CENPE, DLGAP5, KIF14, KIF23, MAD2L1, RACGAP1 and UHRF1) of the 10 genes using qRT-PCR (Figure $4 b$, exemplarily shown for $48 \mathrm{~h}$ ). Taken together, the HDAC11 depletion phenotype characterized by cell accumulation in mitosis and aberrant spindle assembly formation is associated with downregulation of genes required for mitotic cell cycle progression in neuroblastoma cells.

We next turned to two independently existing wholegenome expression profiles from $476^{30}$ and $88^{6}$ primary neuroblastomas to investigate the correlation between overall and event-free survival in patients with tumors expressing CCNE1, CENPA, CENPE, DLGAP5, KIF14, KIF23, MAD2L1, RACGAP1 or UHRF1. High-level expression of each single gene strongly correlated with unfavorable overall and eventfree patient survival in the entire cohort and in the patient subgroup with tumors lacking MYCN amplifications (Table 1; Supplementary Table S3). No major differences in the expression of these genes were observed in the patient subgroup with tumors harboring $M Y C N$ amplifications (data not shown). High-level expression of each single gene also strongly correlated with the expression of each of the other seven genes except CCNE1, supporting the concept of a functionally linked gene group and suggesting a similar pattern of regulation (Supplementary Figure S5, exemplarily shown for the Oberthuer cohort $^{30}$ ). We also assessed expression of the nine genes in high-risk neuroblastomas (as defined by INRG staging ${ }^{31}$ ) with $(n=67)$ and without $(n=77)$ MYCN amplifications in the Kocak tumor cohort. ${ }^{30}$ High-level expression of the 9-gene group was correlated $\left(P=2.08^{\mathrm{e}-08}\right)$ with $M Y C N$ amplification. Neuroblastomas with 
Table 1 Correlation of mRNA expression of HDAC11-regulated genes with patient outcome in the 476 neuroblastoma cohort by Oberthuer et al. ${ }^{30}$

\begin{tabular}{|c|c|c|c|c|c|c|c|c|}
\hline \multirow[b]{2}{*}{ Gene } & \multicolumn{4}{|c|}{ Overall survival/entire cohort } & \multicolumn{4}{|c|}{ Event-free survival/entire cohort } \\
\hline & Cutoff & $n$ (high) & $n$ (low) & $P$-value ${ }^{a}$ & Cutoff & $n$ (high) & $n$ (low) & $P$-value ${ }^{a}$ \\
\hline CCNE1 & 4463.4 & 80 & 396 & $8.4 E^{-22}$ & 4416.3 & 82 & 394 & $1.7 E^{-13}$ \\
\hline CENPA & 1239.5 & 136 & 340 & $5.0 \mathrm{E}^{-24}$ & 1146.9 & 146 & 330 & $4.2 \mathrm{E}^{-22}$ \\
\hline CENPE & 2518.9 & 133 & 343 & $2.0 \mathrm{E}^{-22}$ & 2258.1 & 155 & 321 & $1.7 \mathrm{E}^{-21}$ \\
\hline$D L G A P 5$ & 2443.4 & 142 & 334 & $6.8 \mathrm{E}^{-21}$ & 2158.5 & 160 & 316 & $2.2 E^{-19}$ \\
\hline KIF14 & 293.0 & 169 & 307 & $1.3 E^{-15}$ & 293.0 & 169 & 307 & $5.2 \mathrm{E}^{-14}$ \\
\hline KIF23 & 4447.3 & 93 & 383 & $8.3 E^{-14}$ & 4447.3 & 93 & 383 & $4.4 \mathrm{E}^{-12}$ \\
\hline MAD2L 1 & 6671.7 & 163 & 313 & $1.5 \mathrm{E}^{-22}$ & 6671.7 & 163 & 313 & $1.0 \mathrm{E}^{-20}$ \\
\hline$R A C G A P 1$ & 12864.4 & 63 & 413 & $2.0 \mathrm{E}^{-09}$ & 12949.5 & 61 & 415 & $1.2 \mathrm{E}^{-11}$ \\
\hline \multirow[t]{2}{*}{ UHRF1 } & 2461.8 & 151 & 325 & $2.1 \mathrm{E}^{-27}$ & 2211.7 & 171 & 305 & $8.1 E^{-20}$ \\
\hline & \multicolumn{4}{|c|}{ Overall survival/MYCN single-copy tumors } & \multicolumn{4}{|c|}{ Event-free survival/MYCN single-copy tumors } \\
\hline Gene & Cutoff & $n$ (high) & $n$ (low) & $P$-value ${ }^{a}$ & Cutoff & $n$ (high) & $n$ (low) & $\boldsymbol{P}_{\text {-value }}{ }^{\mathrm{a}}$ \\
\hline CCNE1 & 4463.4 & 40 & 365 & $2.5 E^{-07}$ & 4815.1 & 28 & 377 & $1.4 E^{-06}$ \\
\hline CENPA & 1671.9 & 51 & 354 & $9.3 E^{-11}$ & 1146.9 & 87 & 318 & $1.7 E^{-13}$ \\
\hline CENPE & 2645.6 & 73 & 332 & $1.1 \mathrm{E}^{-11}$ & 2258.1 & 97 & 308 & $8.0 \mathrm{E}^{-16}$ \\
\hline$D L G A P 5$ & 2158.5 & 104 & 301 & $7.9 \mathrm{E}^{-11}$ & 2158.5 & 104 & 301 & $4.7 \mathrm{E}^{-13}$ \\
\hline KIF14 & 617.3 & 23 & 382 & $4.2 \mathrm{E}^{-09}$ & 293.0 & 118 & 287 & $3.4 \mathrm{E}^{-06}$ \\
\hline KIF23 & 4447.3 & 58 & 347 & $3.4 \mathrm{E}^{-06}$ & 2949.5 & 138 & 267 & $2.7 \mathrm{E}^{-07}$ \\
\hline MAD2L 1 & 6898.8 & 97 & 308 & $8.7 \mathrm{E}^{-14}$ & 6696.5 & 100 & 305 & $9.5 \mathrm{E}^{-15}$ \\
\hline$R A C G A P 1$ & 15662.4 & 17 & 388 & $1.4 \mathrm{E}^{-07}$ & 12949.5 & 45 & 360 & $5.1 \mathrm{E}^{-08}$ \\
\hline UHRF1 & 2461.8 & 92 & 313 & $1.7 \mathrm{E}^{-15}$ & 2023.2 & 129 & 276 & $2.8 E^{-14}$ \\
\hline
\end{tabular}

$P$-values were adjusted for multiple testing due to cut-point search according to Lausen ${ }^{84}$

${ }^{a}$ Higher gene expression was always associated with worse prognosis

unfavorable biology and associated dismal patient outcome strongly express this 9-gene group associated with cell cycle progression.

\footnotetext{
Counteracting RACGAP1 downregulation partially rescues caspase 3 induction by HDAC11 depletion. We aimed to test whether enforced expression of one of the 9-gene group downregulated by HDAC11 depletion should partially rescue the cell death phenotype. Both a mediumthroughput CellTiter-Glo assay measuring ATP content and a medium-throughput CaspGlo assay were performed in $B E(2)-C$ and IMR-32 cells after depletion of each of the nine genes to identify the most suitable for the rescue experiment. RNAi targeting the nine genes, each with two different siRNAs, reduced ATP content in BE(2)-C cells by at least $40 \%$ and up to $95 \% 96 \mathrm{~h}$ after transfection (Figure $5 \mathrm{a}$ ). ATP content in IMR-32 cells was diminished by at least $55 \%$ and up to $95 \%$ after knockdown of CCNE1, CENPA, CENPE, KIF14, KIF23 or RACGAP1, whereas targeting DLGAP5, MAD2L1 or UHRF1 did not largely shift ATP content (Figure 5b). Caspase 3-like induction was assessed in cells $72 \mathrm{~h}$ after knockdown of those genes which significantly influenced cellular ATP in both cell lines. In BE(2)-C cells, KIF14 or RACGAP1 knockdown caused a 4.5- to 7.7-fold induction of caspase 3-like activity (Figure 5c). In IMR-32 cells, caspase 3-like activity was triggered 6.5- to 18.2-fold by siRNA-mediated knockdown of CENPE, KIF23 or RACGAP1 (Figure 5d), and RACGAP1 was identified as the most suitable gene for rescue experiments. Plasmid-mediated, enforced RACGAP1 expression to counteract RACGAP1 downregulation by HDAC11 depletion (Supplementary Figures $6 \mathrm{a}-\mathrm{c})$ significantly reduced $(P<0.01)$ induction of
}

caspase 3-like activity, decreased the number of membranepermeable dead $\mathrm{BE}(2)-\mathrm{C}$ cells and enhanced the number of viable $B E(2)-C$ cells compared to HDAC11-depleted $B E(2)-C$ cells transfected with the LacZ expression plasmid (Figures $5 \mathrm{e}-\mathrm{g}$ ), demonstrating the involvement of RACGAP1 downregulation in the HDAC11 depletion phenotype.

\section{Discussion}

Our studies unravel a critical role for HDAC11 in cell cycle progression and viability of $M Y C N$-amplified neuroblastoma cells. We recently reported that HDAC11 transcript levels are significantly higher in several carcinoma entities than corresponding healthy tissues. ${ }^{26}$ HDAC11 depletion was sufficient to inhibit metabolic activity and induce cell death in carcinoma cell lines while having no detectable effects on two different normal cell types, making HDAC11-inhibiting drugs highly interesting for programs searching for new targeted therapeutics to treat breast, colon, ovary and prostate cancers. ${ }^{26}$ These results suggest tumor selectivity and a relatively broad therapeutic window, which is important for the future development of small molecules selectively inhibiting HDAC11. Here we deepen the understanding of HDAC11 function in neuroblastoma. Broad-spectrum HDAC inhibitors have different effects on the cell cycle of transformed cells, including cell cycle arrests in both $\mathrm{G} 1$ and $\mathrm{G} 2 / \mathrm{M}^{32}$ As transformed cells frequently lack a functional G2 checkpoint, cancer cells arrested in G2/M frequently undergo apoptosis. ${ }^{32}$ Our observation that HDAC11-depleted neuroblastoma cells accumulate in G2/M, form aberrant spindle assemblies and subsequently undergo apoptosis suggest the effect elicited by 
a

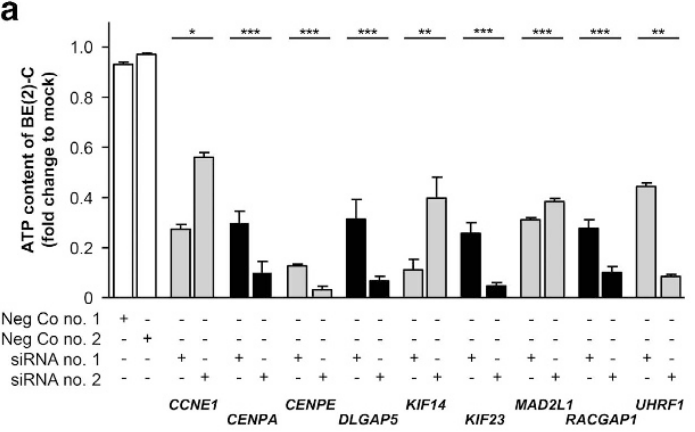

b

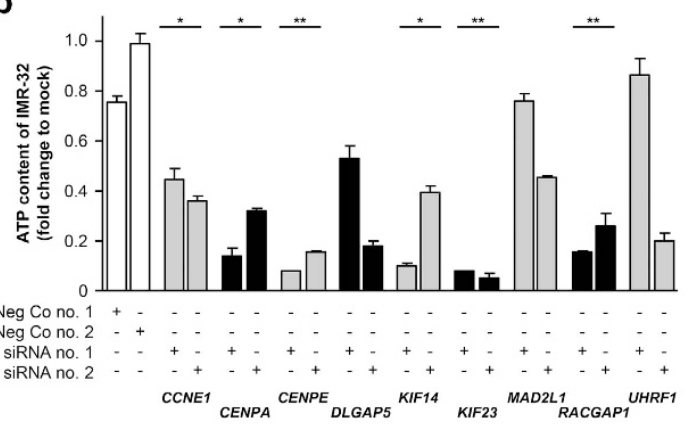

c

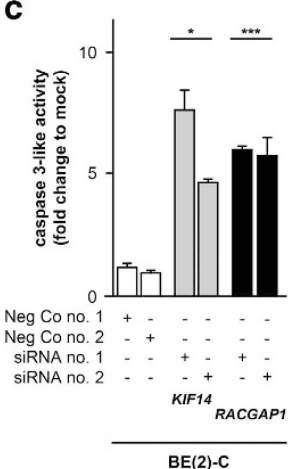

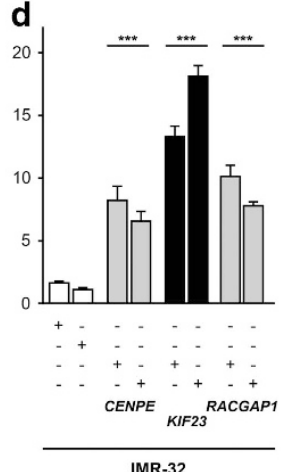

e

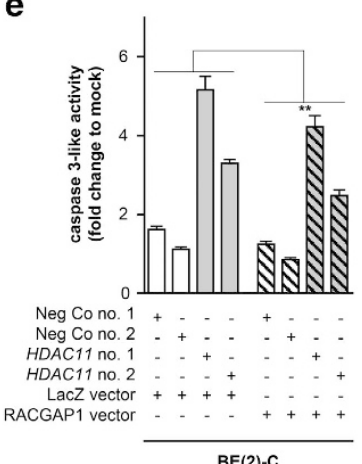

f

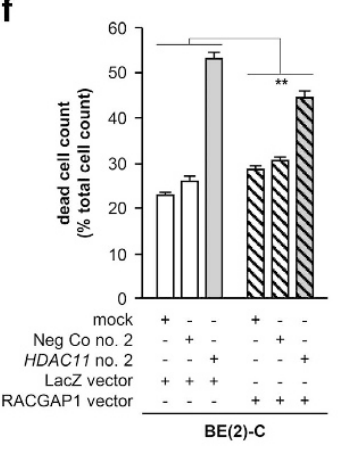

g

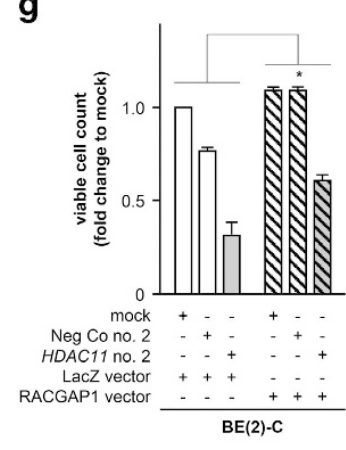

Figure 5 Enforced RACGAP1 expression partially rescues apoptosis triggered by HDAC11 depletion. (a and $\mathbf{b}$ ) Intracellular ATP content of BE(2)-C (a) and IMR-32 cultures (b) $96 \mathrm{~h}$ after transfection with candidate gene-specific or negative control siRNAs (mean fold change over mock-transfected cells \pm S.D. is shown, $n=3$ ). (c and d) Caspase 3-like activity of BE(2)-C (c) and IMR-32 cultures (d) $72 \mathrm{~h}$ after transfection with candidate gene-specific or negative control siRNAs (mean fold changes over mock \pm S.D., $n=3$ ). $(\mathbf{e}-\mathbf{g})$ Caspase 3-like activity (e), dead cell count (f) and viable cell count $(\mathbf{g})$ of $\mathrm{BE}(2)-\mathrm{C}$ cells $72 \mathrm{~h}$ after transfection with HDAC11-specific or negative control siRNAs and $48 \mathrm{~h}$ after transfection of the RACGAP1 plasmid or respective LacZ control (mean fold changes over mock \pm S.D., $n=3$ ). ${ }^{*} P<0.05 ;{ }^{* *} P \leqslant 0.01 ;{ }^{* * *} P \leqslant 0.001$

pan-HDAC inhibition is at least in part mediated by targeting HDAC11.

On a molecular level, downregulation of a 9-gene group required for proper mitotic cell cycle progression was observed in an unbiased transcriptome-wide approach. Knockdown of these genes (CCNE1, CENPA, CENPE, DLGAP5, KIF14, KIF23, MAD2L1, RACGAP1 and UHRF1) by siRNAs recapitulated the HDAC11 depletion phenotype, underlining their importance for mitosis. Counteracting downregulation of one of these genes, RACGAP1, partially rescued the programmed cell death phenotype observed. This supports the functional relevance of RACGAP1 downregulation for the HDAC11 depletion phenotype. High-level mRNA expression of the nine genes correlated with unfavorable patient survival in two independent neuroblastoma cohorts as well as with $M Y C N$ amplification in primary high-risk neuroblastomas. Targeting rapid proliferation in $M Y C N$-amplified neuroblastoma cells by downregulating genes indispensable for cell cycle progression has previously been shown to elicit cell cycle arrest and cell death, and is considered a promising strategy to block the oncogenic effect of MYCN amplification on cell cycle. ${ }^{33}$ The strong phenotype produced by HDAC11 depletion in $M Y C N$-amplified neuroblastoma cell lines supports this approach.

A review of the literature solidifies the importance of the nine genes downregulated by HDAC11 depletion for proper cell cycle progression and division, but also reveals associations with other hallmarks of cancer. Enforced MYCN expression in $\mathrm{SH}-\mathrm{EP}$ cells triggers transcriptional activation of cyclin E1 (CCNE1), and high-level CCNE1 expression correlates with MYCN amplification in primary neuroblastomas. ${ }^{34}$ Ubiquitin like with PHD and ring finger domains 1 (UHRF1) encodes a member of a subfamily of RING finger type E3 ubiquitin ligases that is required for inheriting methylation during S-phase. ${ }^{35}$ Centromere protein A (CENPA) is a histone $\mathrm{H} 3$ variant that epigenetically marks where a centromere will form, and creates a unique more open nucleosome structure allowing recruitment of CENPC and centrosome establishment. ${ }^{36}$ In fact, CENPC alone can trigger kinetochore assembly in defined templates in vitro. ${ }^{37}$ Although CENPA and CENPC are parts of the inner kinetochore, ${ }^{38,39}$ centromere protein $\mathrm{E}$ (CENPE) is a kinesin-like motor protein strongly expressed in G2 and essential for chromosome alignment by connecting the outer kinetochore to the spindle microtubule. ${ }^{40}$ Several studies have established that CENPE knockdown causes G2 blockade, although cell fate following the G2 block appears to rely on other genes expressed in the cell. ${ }^{41}$ Serial transcriptomic analyses of pre-neoplastic ganglia and end-stage tumors in the TH-MYCN transgenic mouse model identified increased CENPE expression during tumor progression, and targeting CENPE with the GSK923295 small-molecule inhibitor reduced proliferation in human neuroblastoma cell lines and tumor growth in three xenograft models. ${ }^{42}$ DLG-associated protein 5 (DLGAP5) is part of a multi- 
component complex and associates with microtubules, thus, mediating stabilization. ${ }^{43}$ Kinesin family member 14 (KIF14) encodes a member of the kinesin-3 superfamily of microtubule motor proteins that acts to bundle and stabilize midbody microtubules during cytokinesis. ${ }^{44}$ KIF14 acts as an oncogene in many cancer entities, including esophageal squamous cell carcinoma, ${ }^{45}$ cervical and ovarian cancers, ${ }^{46,47}$ gliomas, ${ }^{48}$ retinoblastoma, ${ }^{49,50}$ glioblastoma, ${ }^{51}$ hepatocellular carcinoma, ${ }^{52}$ lung adenocarcinoma, ${ }^{53}$ laryngeal carcinoma, ${ }^{54}$ synovial carcinomas ${ }^{55}$ and papillary renal cell tumors. ${ }^{56}$ KIF14 is present in the minimal region of chromosome 1q gain in breast cancer cell lines, is overexpressed in breast cancers and its expression positively correlates with tumor aggressiveness. ${ }^{57,58}$ KIF14 not only drives cell proliferation, but has been shown to promote chemoresistance via AKT signaling in triple-negative breast cance ${ }^{59}$ and enhance metastatic and invasive capacity during breast cancer progression via RAP1A-RADIL signaling inhibition. ${ }^{60}$ KIF14 is also a key gene necessary for perineural invasion by pancreatic carcinoma. ${ }^{61}$ High-level KIF14 expression has also been reported in cell lines derived from medulloblastomas. ${ }^{62}$ Together with the results we report here, these data show that KIF14 hyperactivity resulting from direct genomic gain or gene upregulation via epigenetic or other mechanisms is associated with the most aggressive subgroups of not only adult cancers but most pediatric embryonal tumors. It is interesting to note that KIF14 expression is associated with the more aggressive tumor types of all carcinoma types reported to be sensitive to HDAC11 inhibition. ${ }^{26}$ The MAD2 mitotic arrest deficient-like 1 protein (MAD2L1) is a component of the mitotic spindle assembly checkpoint that delays anaphase onset until all chromosomes are properly aligned at the metaphase plate. ${ }^{63}$ KIF23 is part of the 157-gene signature for MYCN activity identified by shRNA-mediated MYCN silencing in neuroblastoma cells and confirmed by expression studies in 88 neuroblastomas. ${ }^{64}$ KIF23 and Rac GTPase activating protein 1 (RACGAP1) are highly expressed during G2/M. ${ }^{65,66}$ RACGAP1 and KIF23 form the centralspindlin complex, ${ }^{67}$ a motor complex essential for virtually every step in cytokinesis including mitotic spindle formation and anchoring. Absence of either protein leads to failure of cytokinesis due to deficient central spindle assembly and contractile ring formation. ${ }^{68}$ The aberrant spindle assembly formation we observed in HDAC11-depleted neuroblastoma cells suggests that HDAC11 disrupts the complex machinery regulating these processes, likely via KIF23, MAD2L1 and RACGAP1. Highlevel RACGAP1 expression was also observed in different cancer entities. ${ }^{69-72}$ The nine genes we show downregulated by HDAC11 depletion in G2/M-arrested neuroblastoma cells all play an important role in proper cell cycle progression and division, but some are also key players in cancer hallmarks associated with progression to more aggressive tumor phenotypes, including development of chemoresistance, metastases and invasive potential. HDAC11 may provide a druggable regulatory node to reduce many functions necessary for developing aggressiveness in multiple cancers affecting adults and children.

Our previous investigations unraveled specific and nonredundant oncogenic functions of HDAC2/3/5/8/10 in neuroblastoma pathophysiology. ${ }^{19,20,23,73,74}$ The clinical application of pan-HDAC inhibitors showed dose-limiting toxicities, which is not surprising considering the central role of HDACs in modulating chromatin structure and cytoplasmic processes such as autophagy. Selective inhibitors may improve antitumoral efficacy, and have already been successfully developed against single HDACs. HDAC11-selective inhibitors have as yet not been developed. Here we show that HDAC11 depletion in $M Y C N$-amplified neuroblastoma cells triggers programmed cell death preceded by an accumulation of mitotic cells characterized by aberrant spindle assembly formation. On a molecular level, downregulation of a 9-gene group required for proper mitotic cell cycle progression was observed in an unbiased transcriptome-wide approach, and counteracting RACGAP1 downregulation by HDAC11 depletion partially rescued the programmed cell death phenotype observed. The 9-gene group includes KIF14, a known oncogene associated with aggressive tumor qualities in many cancers, linking HDAC11 epigenetic regulation to the hallmarks of aggressive cancers. Taken together, our data illustrate an important role for HDAC11 in cell cycle progression and viability of $M Y C N$-amplified neuroblastoma cells, and illuminates HDAC11 as a potential novel drug target for this subgroup of high-risk neuroblastomas.

\section{Materials and Methods}

Cell culture and chemicals. The BE(2)-C and SK-N-AS neuroblastoma cell lines were obtained from ECACC (Salisbury, UK), and the IMR-32 and SH-SY5Y cell lines from the DSMZ (Braunschweig, Germany). Cell lines were monitored for infections by high-throughput multiplex cell contamination testing. ${ }^{75}$ Cell line authenticity was validated by high-throughput SNP-based assays. ${ }^{76} \mathrm{BE}(2)-\mathrm{C}, \mathrm{SK}-\mathrm{N}$ AS, IMR-32 and SK-N-AS cell lines were cultured in DMEM (Lonza, Basel, Switzerland) supplemented with 10\% FCS (Sigma-Aldrich, Hamburg, Germany) and $1 \%$ non-essential amino acids (NEAA; Lonza) at $37^{\circ} \mathrm{C}$ and $5 \% \mathrm{CO}_{2}$. The broad range caspase inhibitor, zVAD.fmk (Bachem, Heidelberg, Germany), was directly added to the cell culture medium to obtain a final concentration of $20 \mu \mathrm{M}$, whereas controls were treated with DMSO.

Microscopy. Living native cells were examined with an inverted widefield microscope (Olympus CKX41, Tokyo, Japan). Software Cell^B (Olympus) was used for the acquisition of microscopic images. Fixed, DAPI-labeled cells were viewed under both the Olympus CKX 41 and a laser-scanning confocal microscope (Zeiss LSM700, Oberkochen, Germany) equipped with the ZEN 2012 blue edition software (Zeiss). Operators performing the quantification of DAPI-labeled mitotic cells were blinded to the treatment group. Positive cells were counted using the Cell $\mathrm{B}$ software (Olympus) counting tool.

Transfection of siRNAs and DNA plasmids. For knockdown experiments, cells were transiently transfected with $25 \mathrm{nM}$ siRNA (Supplementary Table S1) using the HiPerFect method (Qiagen, Hilden, Germany) according to the manufacturer's directions. For plasmid transfection, the Effectene method (Qiagen) was used according to the manufacturer's manual. Applying the GATEWAY technology (Invitrogen, Carlsbad, CA, USA), the RACGAP1 complementary DNA (cDNA) sequence (EU176264) was cloned from the pENTR221 vector into the destination vector pT-REx-DEST30. The empty pT-REx-DEST30 vector and the LacZ expression vector, pT-REx/GW30/LacZ (Invitrogen), served as controls. For the expression of Myc-tagged HDAC11, the MYC tag sequence (MEQKLISEEDL) was N-terminally inserted into the expression vector pcDNA3.1 carrying the wild-type HDAC11 sequence. ${ }^{19}$ The correct sequences of all inserts were verified by DNA sequencing (GATC, Konstanz, Germany).

RNA extraction, cDNA synthesis and qRT-PCR. Total RNA was isolated from $B E(2)-C$ and IMR-32 cell lines using the RNeasy Mini Kit (Qiagen). The Thermo Scientific First-Strand cDNA Synthesis Kit (Thermo Scientific, Waltham, MA, USA) was used to transcribe cDNAs for qRT-PCR analysis. Relative gene expression was measured using SYBR Green Dye (Eurogentec, Cologne, 
Germany) on an ABI Prism 7500 thermal cycler (Perkin-Elmer Applied Biosystems, Weiterstadt, Germany). All primers used in GRT-PCR are listed in the Supplementary Table S2. Data were analyzed using Applied Biosystems 7500 software v2.0.5 (Thermo Scientific), and changes in gene expression were calculated using the $\Delta \Delta C_{\mathrm{t}}$ method.

Western blotting. Western blots were performed as described ${ }^{19,77}$ using the following antibodies: mouse monoclonal anti- $\beta$-actin (clone AC-15, Sigma-Aldrich, St. Louis, MO, USA), rabbit polyclonal anti-CASP3 (Cell Signaling, Danvers, MA, USA), mouse monoclonal anti-GAPDH (clone 6C5; Merck Millipore, Darmstadt, Germany), mouse monoclonal anti-HDAC1 (clone 10E2; Abcam, Cambridge, UK), mouse monoclonal anti-HDAC2 (clone 3F3; Abcam), rabbit polyclonal anti-HDAC3 (clone H-99; Santa Cruz Biotechnology, Dallas, TX, USA), rabbit polyclonal anti-HDAC8 (Abcam), mouse monoclonal anti-MYC tag (GeneTex, Irvine, CA, USA), mouse monoclonal anti-PARP (Cell Signaling), mouse monoclonal anti-phospho H3 (Ser10) (Cell Signaling), rabbit monoclonal anti-histone H3 (Cell Signaling) and rabbit polyclonal anti-RACGAP1 (Santa Cruz Biotechnology). Band density was analyzed using ImageJ 1.47p software (Wayne Rasband, National Institute of Health, Bethesda, MD, USA) on western blots, and results were normalized to the respective loading controls.

Trypan blue exclusion and CellTiter-Glo assays. Cell number and viability were semi-automatically measured with the VI-CELL Cell Viability Analyzer (Beckman, Krefeld, Germany) based on the trypan blue exclusion method. ${ }^{20}$ The CellTiter-Glo luminescent cell viability assay (Promega, Fitchburg, WI, USA) was used according to the manufacturer's directions to measure the amount of intracellular ATP.

Flow cytometry. Cell cycle distribution and DNA fragmentation was determined on a FACS Calibur flow cytometer (BD Biosciences, Heidelberg, Germany) using the CellQuest Pro software (BD Biosciences) after cell nuclei were stained with propidium iodide. ${ }^{19}$ The FITC Annexin V Apoptosis Detection Kit I (BD Pharmingen, Heidelberg, Germany) was used to quantify phosphatidylserine at the outer cell membrane.

Caspase activity assay. Cells were seeded, treated as indicated, collected with supernatant and lysed in cell lysis buffer (Biovision, Mountain View, CA, USA) for $10 \mathrm{~min}$ on ice. Protein concentrations were normalized using the Pierce assay. Thereafter, reaction buffer (MBL International, Woburn, MA, USA) and AFC-labeled caspase 3-specific peptide, DEVD (Biomol, Hamburg, Germany), were added. Caspase 3-like activity was measured at $37^{\circ} \mathrm{C}$ in black 96-well plates using a fluorescence plate reader with a $380 \mathrm{~nm}$ excitation filter and a $530 \mathrm{~nm}$ emission filter. ${ }^{19}$ The Caspase Glo $3 / 7$ assay (Promega) facilitating direct measurements without cell harvest and lysis was used for medium-throughput analyses, and results were normalized to the amount of intracellular ATP measured by the CellTiterGlo assay.

Probe labeling, Illumina Sentrix BeadChip array hybridization and microarray scanning. RNA isolated from cell lines as described above was resuspended in TE buffer and eluted in water. Quality of total RNA was checked by gel analysis using the total RNA NanoChip Assay on an Agilent 2100 Bioanalyzer (Agilent Technologies GmbH, Berlin, Germany). Samples with RNA indices $>8.5$ were selected for expression profiling. RNA concentrations were determined with a NanoDrop spectrophotometer (NanoDrop Technologies, Wilmington, DE, USA). Biotin-labeled cRNA samples were prepared for hybridization on Illumina Human Sentrix-12 BeadChip arrays (Illumina Inc., San Diego, CA, USA) according to the sample labeling procedure recommended by Illumina with minor modifications. ${ }^{78}$ In brief, $250 \mathrm{ng}$ total RNA was used for cDNA synthesis, followed by an amplification and labeling step to synthesize biotin-labeled cRNA according to the Illumina TotalPrep RNA Amplification Kit (Life Technologies, Carlsbad, CA, USA). The cRNA was column-purified with the TotalPrep RNA Amplification Kit and eluted in $60 \mu \mathrm{l}$ of water. The cRNA quality was controlled with the RNA NanoChip Assay on an Agilent 2100 Bioanalyzer, and the cRNA content was spectrophotometrically quantified with a NanoDrop.

Hybridization was performed at $58^{\circ} \mathrm{C}$ in GEX-HCB buffer (Illumina Inc.) at a concentration of $100 \mathrm{ng} \mathrm{cRNA} / \mu \mathrm{l}$, unsealed in a wet chamber for $20 \mathrm{~h}$. Thereafter, mismatch control oligonucleotides, biotinylation control oligonucleotides and spike-in controls for low-, medium- and highly abundant RNAs were added. Microarrays were washed once in High Temp Wash buffer (Illumina Inc.) at $55^{\circ} \mathrm{C}$ and twice in E1BC buffer (Illumina Inc.) at room temperature for $5 \mathrm{~min}$. In between, microarrays were washed with ethanol at room temperature. After blocking for $5 \mathrm{~min}$ in $4 \mathrm{ml}$ of $1 \%(\mathrm{w} / \mathrm{v})$ Blocker Casein in phosphate-buffered saline Hammarsten grade (Pierce Biotechnology Inc., Rockford, IL, USA), array signals were developed by a 10 min incubation in $2 \mathrm{ml}$ of $1 \mu \mathrm{g} / \mathrm{ml}$ Cy3-streptavidin solution (Amersham Biosciences, Buckinghamshire, $\mathrm{UK}$ ) and $1 \%$ blocking solution. After a final wash in E1BC, microarrays were dried and scanned using an iScan array scanner. Data extraction was done for all beads individually. Outliers, identified as having $>2.5$ MAD (median absolute deviation), were removed. All remaining data points were used for the calculation of the mean average signal and S.D. for a given probe. The data discussed in this publication have been deposited in NCBI's Gene Expression Omnibus ${ }^{79}$ and are accessible through GEO Series accession number GSE77080 (http://www.ncbi.nlm.nih.gov/geo/query/ acc.cgi?acc=GSE77080).

Statistical analysis. Microarray data obtained in duplicates were normalized using quantile normalization in the 'R programming language'. Quantile-normalized Illumina mRNA data were $\log _{2}$ transformed. Differentially expressed transcripts were identified for each HDAC11 siRNA separately in comparison to the negative control transfection using the empirical Bayes approach as implemented in the Bioconductor package limma. ${ }^{80}$ Time points were tested globally using moderated F-statistics and individually using moderated $t$-statistics, both based on the same linear model. All $P$-values were adjusted for multiple testing using the BenjaminiHochberg correction. ${ }^{81}$ Next, transcripts that showed a significant regulation at two or more time points in the same direction and no significant regulation in the opposite direction, were selected. The overlap of these selected transcripts from both siRNAs defined the primary list of regulated transcripts (hits). This analysis was performed separately for each cell line. GO terms were analyzed for overrepresentation and enrichment. First, hypergeometric tests were used to test for over-representation of GO terms within the hit list. Second, a gene set enrichment analysis was performed using the minimal F-statistics from both siRNA models as a global measurement of regulation. Taking the minimal moderated F-statistic value from both linear models can be considered a conservative approach because the lesser strength of regulation from both siRNAs is selected to represent the transcript, thus mimicking the requirement to show regulation in both siRNAs. In case multiple transcripts mapped to the same Entrez Gene ID, duplicates were removed for both analyses by using only the transcript that showed the strongest regulation to represent the gene. Again, $P$-values were adjusted for multiple testing using Benjamini-Hochberg correction. ${ }^{81} \mathrm{GO}$ analyses were carried out for each cell line separately with the Bioconductor package HTSanalyzeR. ${ }^{82} \mathrm{GO}$ terms showing both a significant over-representation and enrichment were selected for further investigation. All analyses were carried out using $\mathrm{R}^{83}$ and all tests were two-sided.

Effects of HDAC11 depletion on phenotype compared to those of negative control siRNA transfection were analyzed by a mixed linear model with a fixed effect for HDAC11-depleted samples in comparison to negative control treated cultures and random intercept for each individual HDAC11 or negative control siRNA using SAS PROC MIXED, SAS Version 9.2 (SAS Institute Inc., Cary, NC, USA). Comparison of qRT-PCR data was performed with a paired two-tailed $t$-test (GraphPad Prism version 5.01, GraphPad Software, Inc., La Jolla, CA, USA). P-values below 0.05 were considered statistically significant.

\section{Conflict of Interest}

The authors declare no conflict of interest.

Acknowledgements. We wish to thank Kathy Astrahantseff for comments on and editing of the manuscript, the German Neuroblastoma Tumor Bank (Cologne) for providing tumor samples, and the Imaging and Cytometry Core Facility of the DKFZ for their valuable services. This work was supported by the BMBF through e:MED SYSMED-NB (M Fischer, A Eggert, HE Deubzer), by the Berlin Institute of Health (BIH) through TERMINATE-NB (A Eggert, HE Deubzer) and a translational PhD project grant (HE Deubzer), by the Deutsche Krebshilfe (M Lodrini, HE Deubzer) and by the Kind-Philipp-Stiftung through a doctoral scholarship (TM Thole).

1. Maris JM. Recent advances in neuroblastoma. New Engl J Med 2010; 362: 2202-2211.

2. Schwab M, Alitalo K, Klempnauer KH, Varmus HE, Bishop JM, Gilbert F et al. Amplified DNA with limited homology to myc cellular oncogene is shared by human neuroblastoma cell lines and a neuroblastoma tumour. Nature 1983; 305: 245-248. 
3. Brodeur GM, Seeger RC, Schwab M, Varmus HE, Bishop JM. Amplification of N-myc in untreated human neuroblastomas correlates with advanced disease stage. Science 1984 224: 1121-1124

4. Peifer M, Hertwig F, Roels F, Dreidax D, Gartlgruber M, Menon R et al. Telomerase activation by genomic rearrangements in high-risk neuroblastoma. Nature 2015; 526: 700-704.

5. Valentijn LJ, Koster J, Zwijnenburg DA, Hasselt NE, van Sluis P, Volckmann R et al. TERT rearrangements are frequent in neuroblastoma and identify aggressive tumors. Nat Genet 2015; 47: 1411-1414.

6. Molenaar JJ, Koster J, Zwijnenburg DA, van Sluis P, Valentijn LJ, van der Ploeg I et al. Sequencing of neuroblastoma identifies chromothripsis and defects in neuritogenesis genes. Nature 2012; 483: 589-593.

7. Mosse YP, Laudenslager M, Longo L, Cole KA, Wood A, Attiyeh EF et al. Identification of ALK as a major familial neuroblastoma predisposition gene. Nature 2008; 455: 930-935.

8. Chen Y, Takita J, Choi YL, Kato M, Ohira M, Sanada M et al. Oncogenic mutations of ALK kinase in neuroblastoma. Nature 2008; 455: 971-974.

9. Janoueix-Lerosey I, Lequin D, Brugieres L, Ribeiro A, de Pontual L, Combaret V et al. Somatic and germline activating mutations of the ALK kinase receptor in neuroblastoma Nature 2008; 455: 967-970.

10. George RE, Sanda T, Hanna M, Frohling S, Luther W 2nd, Zhang J et al. Activating mutations in ALK provide a therapeutic target in neuroblastoma. Nature 2008; 455: 975-978.

11. Witt $\mathrm{O}$, Deubzer HE, Lodrini M, Milde T, Oehme I. Targeting histone deacetylases in neuroblastoma. Curr Pharm Des 2009; 15: 436-447.

12. Gustafson WC, Meyerowitz JG, Nekritz EA, Chen J, Benes C, Charron E et al. Drugging MYCN through an allosteric transition in Aurora kinase A. Cancer Cell 2014; 26: 414-427.

13. Henssen A, Althoff K, Odersky A, Beckers A, Koche R, Speleman F et al. Targeting MYCN-driven transcription by BET-bromodomain inhibition. Clin Cancer Res 2016; 22 2470-2481.

14. Lakoma A, Barbieri E, Agarwal S, Jackson J, Chen Z, Kim Y et al. The MDM2 small-molecule inhibitor RG7388 leads to potent tumor inhibition in p53 wild-type neuroblastoma. Cell Death Discov 2015; 1: 15026.

15. Woodfield SE, Zhang L, Scorsone KA, Liu Y, Zage PE. Binimetinib inhibits MEK and is effective against neuroblastoma tumor cells with low NF1 expression. BMC Cancer 2016; 16 172

16. Rader J, Russell MR, Hart LS, Nakazawa MS, Belcastro LT, Martinez D et al. Dual CDK4/CDK6 inhibition induces cell-cycle arrest and senescence in neuroblastoma. Clin Cancer Res 2013; 19: 6173-6182.

17. Juo YY, Gong XJ, Mishra A, Cui X, Baylin SB, Azad NS et al. Epigenetic therapy for solid tumors: from bench science to clinical trials. Epigenomics 2015; 7: 215-235.

18. Liu T, Tee AE, Porro A, Smith SA, Dwarte T, Liu PY et al. Activation of tissue transglutaminase transcription by histone deacetylase inhibition as a therapeutic approach for Myc oncogenesis. Proc Natl Acad Sci USA 2007; 104: 18682-18687.

19. Lodrini M, Oehme I, Schroeder C, Milde T, Schier MC, Kopp-Schneider A et al. MYCN and HDAC2 cooperate to repress miR-183 signaling in neuroblastoma. Nucleic Acids Res 2013 41: 6018-6033.

20. Fabian J, Lodrini M, Oehme I, Schier MC, Thole TM, Hielscher T et al. GRHL1 acts as tumor suppressor in neuroblastoma and is negatively regulated by MYCN and HDAC3. Cancer Res 2014; 74: 2604-2616

21. Sun Y, Liu PY, Scarlett CJ, Malyukova A, Liu B, Marshall GM et al. Histone deacetylase 5 blocks neuroblastoma cell differentiation by interacting with N-Myc. Oncogene 2014; 33 : 2987-2994.

22. Rettig I, Koeneke E, Trippel F, Mueller WC, Burhenne J, Kopp-Schneider A et al. Selective inhibition of HDAC8 decreases neuroblastoma growth in vitro and in vivo and enhances retinoic acid-mediated differentiation. Cell Death Dis 2015; 6: e1657.

23. Oehme I, Linke JP, Bock BC, Milde T, Lodrini M, Hartenstein B et al. Histone deacetylase 10 promotes autophagy-mediated cell survival. Proc Natl Acad Sci USA 2013; 110: E2592-E2601.

24. Gao L, Cueto MA, Asselbergs F, Atadja P. Cloning and functional characterization of HDAC11, a novel member of the human histone deacetylase family. J Biol Chem 2002; 277 25748-25755.

25. Glozak MA, Seto E. Acetylation/deacetylation modulates the stability of DNA replication licensing factor Cdt1. J Biol Chem 2009; 284: 11446-11453.

26. Deubzer HE, Schier MC, Oehme I, Lodrini M, Haendler B, Sommer A et al. HDAC11 is a novel drug target in carcinomas. Int J Cancer 2013; 132: 2200-2208.

27. Biedler JL, Spengler BA. A novel chromosome abnormality in human neuroblastoma and antifolate-resistant Chinese hamster cell lives in culture. J Natl Cancer Inst 1976; 57: 683-695.

28. Tweddle DA, Malcolm AJ, Bown N, Pearson AD, Lunec J. Evidence for the development of p53 mutations after cytotoxic therapy in a neuroblastoma cell line. Cancer Res 2001; 61: $8-13$

29. De Brouwer S, De Preter K, Kumps C, Zabrocki P, Porcu M, Westerhout EM et al. Metaanalysis of neuroblastomas reveals a skewed ALK mutation spectrum in tumors with MYCN amplification. Clin Cancer Res 2010; 16: 4353-4362.

30. Oberthuer A, Hero B, Berthold F, Juraeva D, Faldum A, Kahlert $Y$ et al. Prognostic impact of gene expression-based classification for neuroblastoma. J Clin Oncol 2010; 28: 3506-3515.

31. Cohn SL, Pearson AD, London WB, Monclair T, Ambros PF, Brodeur GM et al. The International Neuroblastoma Risk Group (INRG) classification system: an INRG Task Force report. J Clin Oncol 2009; 27: 289-297.
32. Khan O, La Thangue NB. HDAC inhibitors in cancer biology: emerging mechanisms and clinical applications. Immunol Cell Biol 2012; 90: 85-94.

33. Chipumuro E, Marco E, Christensen CL, Kwiatkowski N, Zhang T, Hatheway CM et al. CDK7 inhibition suppresses super-enhancer-linked oncogenic transcription in MYCN-driven cancer. Cell 2014; 159: 1126-1139.

34. Mao L, Ding J, Perdue A, Yang L, Zha Y, Ren M et al. Cyclin E1 is a common target of BMl1 and MYCN and a prognostic marker for neuroblastoma progression. Oncogene 2012; 31: 3785-3795.

35. Bostick M, Kim JK, Esteve PO, Clark A, Pradhan S, Jacobsen SE. UHRF1 plays a role in maintaining DNA methylation in mammalian cells. Science 2007; 317: 1760-1764.

36. Falk SJ, Lee J, Sekulic N, Sennett MA, Lee TH, Black BE. CENP-C directs a structural transition of CENP-A nucleosomes mainly through sliding of DNA gyres. Nat Struct Mol Biol 2016; 23: 204-208.

37. Guse A, Carroll CW, Moree B, Fuller CJ, Straight AF. In vitro centromere and kinetochore assembly on defined chromatin templates. Nature 2011; 477: 354-358.

38. Zlotorynski E. Chromosome biology: controlling CENPA mislocalization. Nat Rev Mol Cell Biol 2014; 15: 368.

39. Hori T, Okada M, Maenaka K, Fukagawa T. CENP-O class proteins form a stable complex and are required for proper kinetochore function. Mol Biol Cell 2008; 19: 843-854.

40. Li T, Chen L, Cheng J, Dai J, Huang Y, Zhang J et al. SUMOylated NKAP is essential for chromosome alignment by anchoring CENP-E to kinetochores. Nat Commun 2016; 7: 12969.

41. Hou S, Li N, Zhang Q, Li H, Wei X. Hao T et al. XAB2 functions in mitotic cell cycle progression via transcriptional regulation of CENPE. Cell Death Dis 2016; 7: e2409.

42. Balamuth NJ, Wood A, Wang $Q$, Jagannathan J, Mayes $P$, Zhang $Z$ et al. Serial transcriptome analysis and cross-species integration identifies centromere-associated protein E as a novel neuroblastoma target. Cancer Res 2010; 70: 2749-2758.

43. Koffa MD, Casanova CM, Santarella R, Kocher T, Wilm M, Mattaj IW. HURP is part of a Randependent complex involved in spindle formation. Curr Biol 2006; 16: 743-754.

44. Rice S. Structure of kif14: an engaging molecular motor. J Mol Biol 2014; 426: 2993-2996.

45. Osako Y, Seki N, Kita Y, Yonemori K, Koshizuka K, Kurozumi A et al. Regulation of MMP13 by antitumor microRNA-375 markedly inhibits cancer cell migration and invasion in esophageal squamous cell carcinoma. Int J Oncol 2016; 49: 2255-2264.

46. Wang W, Shi Y, Li J, Cui W, Yang B. Up-regulation of KIF14 is a predictor of poor survival and a novel prognostic biomarker of chemoresistance to paclitaxel treatment in cervical cancer. Biosci Rep 2016; 36: e00315.

47. Theriault BL, Cybulska P, Shaw PA, Gallie BL, Bernardini MQ. The role of KIF14 in patientderived primary cultures of high-grade serous ovarian cancer cells. J Ovarian Res 2014; 7: 123.

48. Wang Q, Wang L, Li D, Deng J, Zhao Z, He S et al. Kinesin family member 14 is a candidate prognostic marker for outcome of glioma patients. Cancer Epidemiol 2013; 37: 79-84.

49. Madhavan J, Mitra M, Mallikarjuna K, Pranav O, Srinivasan R, Nagpal A et al. KIF14 and E2F3 mRNA expression in human retinoblastoma and its phenotype association. Mol Vis 2009; 15: 235-240.

50. O'Hare M, Shadmand M, Sulaiman RS, Sishtla K, Sakisaka T, Corson TW. Kif14 overexpression accelerates murine retinoblastoma development. Int J Cancer 2016; 139: $1752-1758$.

51. Huang W, Wang J, Zhang D, Chen W, Hou L, Wu X et al. Inhibition of KIF14 suppresses tumor cell growth and promotes apoptosis in human glioblastoma. Cell Physiol Biochem 2015; 37: 1659-1670.

52. Yang T, Zhang XB, Zheng ZM. Suppression of KIF14 expression inhibits hepatocellular carcinoma progression and predicts favorable outcome. Cancer Sci 2013; 104: 552-557.

53. Hung PF, Hong TM, Hsu YC, Chen HY, Chang YL, Wu CT et al. The motor protein KIF14 inhibits tumor growth and cancer metastasis in lung adenocarcinoma. PLOS ONE 2013; 8: e61664.

54. Markowski J, Tyszkiewicz T, Jarzab M, Oczko-Wojciechowska M, Gierek T, Witkowska M et al. Metal-proteinase ADAM12, kinesin 14 and checkpoint suppressor 1 as new molecular markers of laryngeal carcinoma. Eur Arch Otorhinolaryngol 2009; 266: 1501-1507.

55. Lagarde P, Przybyl J, Brulard C, Perot G, Pierron G, Delattre $O$ et al. Chromosome instability accounts for reverse metastatic outcomes of pediatric and adult synovial sarcomas. J Clin Oncol 2013; 31: 608-615.

56. Szponar A, Zubakov D, Pawlak J, Jauch A, Kovacs G. Three genetic developmental stages of papillary renal cell tumors: duplication of chromosome 1q marks fatal progression. Int J Cancer 2009; 124: 2071-2076.

57. Corson TW, Gallie BL. KIF14 mRNA expression is a predictor of grade and outcome in breast cancer. Int J Cancer 2006; 119: 1088-1094.

58. Brynychova V, Ehrlichova M, Hlavac V, Nemcova-Furstova V, Pecha V, Leva J et al. Genetic and functional analyses do not explain the association of high PRC1 expression with poor survival of breast carcinoma patients. Biomed Pharmacother 2016; 83: 857-864.

59. Singel SM, Cornelius C, Zaganjor E, Batten K, Sarode VR, Buckley DL et al. KIF14 promotes AKT phosphorylation and contributes to chemoresistance in triple-negative breast cancer. Neoplasia 2014; 16: 247-256, e242.

60. Ahmed SM, Theriault BL, Uppalapati M, Chiu CW, Gallie BL, Sidhu SS et al. KIF14 negatively regulates Rap1a-Radil signaling during breast cancer progression. J Cell Biol 2012; 199: 951-967.

61. Abiatari I, DeOliveira T, Kerkadze V, Schwager C, Esposito I, Giese NA et al. Consensus transcriptome signature of perineural invasion in pancreatic carcinoma. Mol Cancer Ther 2009; 8: 1494-1504. 
62. Corson TW, Huang A, Tsao MS, Gallie BL. KIF14 is a candidate oncogene in the 1q minimal region of genomic gain in multiple cancers. Oncogene 2005; 24: 4741-4753.

63. Li Y, Benezra R. Identification of a human mitotic checkpoint gene: hsMAD2. Science 1996; 274: 246-248.

64. Valentijn LJ, Koster J, Haneveld F, Aissa RA, van Sluis P, Broekmans ME et al. Functional MYCN signature predicts outcome of neuroblastoma irrespective of MYCN amplification. Proc Natl Acad Sci USA 2012; 109: 19190-19195.

65. Fischer M, Grundke I, Sohr S, Quaas M, Hoffmann S, Knorck A et al. p53 and cell cycle dependent transcription of kinesin family member 23 (KIF23) is controlled via a CHR promoter element bound by DREAM and MMB complexes. PLOS ONE 2013; 8: e63187.

66. Nishimura K, Oki T, Kitaura J, Kuninaka S, Saya H, Sakaue-Sawano A et al. APC(CDH1) targets MgcRacGAP for destruction in the late M phase. PLOS ONE 2013; 8: e63001.

67. Mishima M, Kaitna S, Glotzer M. Central spindle assembly and cytokinesis require a kinesinlike protein/RhoGAP complex with microtubule bundling activity. Dev Cell 2002; 2: 41-54.

68. Canman JC, Lewellyn L, Laband K, Smerdon SJ, Desai A, Bowerman B et al. Inhibition of Rac by the GAP activity of centralspindlin is essential for cytokinesis. Science 2008; 322 : 1543-1546.

69. Pliarchopoulou K, Kalogeras KT, Kronenwett R, Wirtz RM, Eleftheraki AG, Batistatou A et al. Prognostic significance of RACGAP1 mRNA expression in high-risk early breast cancer: a study in primary tumors of breast cancer patients participating in a randomized Hellenic Cooperative Oncology Group trial. Cancer Chemother Pharmacol 2013; 71: 245-255.

70. Wang SM, Ooi LL, Hui KM. Upregulation of Rac GTPase-activating protein 1 is significantly associated with the early recurrence of human hepatocellular carcinoma. Clin Cancer Res 2011; 17: 6040-6051.

71. Ke HL, Ke RH, Li ST, Li B, Lu HT, Wang XQ. Expression of RACGAP1 in high grade meningiomas: a potential role in cancer progression. J Neurooncol 2013; 113: 327-332.

72. Liang Y, Liu M, Wang P, Ding X, Cao Y. Analysis of 20 genes at chromosome band 12q13: RACGAP1 and MCRS1 overexpression in nonsmall-cell lung cancer. Genes Chromosomes Cancer 2013; 52: 305-315.

73. Fabian J, Opitz D, Althoff K, Lodrini M, Hero B, Volland R et al. MYCN and HDAC5 transcriptionally repress $\mathrm{CD} 9$ to trigger invasion and metastasis in neuroblastoma. Oncotarget 2016; 7: 66344-66359.

74. Oehme I, Deubzer HE, Wegener D, Pickert D, Linke JP, Hero B et al. Histone deacetylase 8 in neuroblastoma tumorigenesis. Clin Cancer Res 2009; 15: 91-99.

75. Schmitt M, Pawlita M. High-throughput detection and multiplex identification of cell contaminations. Nucleic Acids Res 2009; 37: e119.
76. Castro F, Dirks WG, Fahnrich S, Hotz-Wagenblatt A, Pawlita M, Schmitt M. High-throughput SNP-based authentication of human cell lines. Int J Cancer 2013; 132: 308-314.

77. Heinicke U, Kupka J, Fichter I, Fulda S. Critical role of mitochondria-mediated apoptosis for JNJ-26481585-induced antitumor activity in rhabdomyosarcoma. Oncogene 2016; 35: 3729-3741

78. Eberwine J, Yeh $\mathrm{H}$, Miyashiro K, Cao Y, Nair S, Finnell R et al. Analysis of gene expression in single live neurons. Proc Natl Acad Sci USA 1992; 89: 3010-3014.

79. Edgar R, Domrachev M, Lash AE. Gene Expression Omnibus: NCBI gene expression and hybridization array data repository. Nucleic Acids Res 2002; 30: 207-210.

80. Smyth GK. Linear models and empirical Bayes methods for assessing differential expression in microarray experiments. Stat Appl Genet Mol Biol 2004: 3. Article3.

81. Benjamini $Y$, Hochberg $Y$. Controlling the false discovery rate: a practical and powerful approach to multiple testing. J R Stat Soc Series B Methodol 1995; 57: 289-300.

82. Wang X, Terfve C, Rose JC, Markowetz F. HTSanalyzeR: an R/Bioconductor package for integrated network analysis of high-throughput screens. Bioinformatics 2011; 27: 879-880.

83. RFfSC RDCT. R: A Language and Environment for Statistical Computing. R Foundation for Statistical Computing. Vienna, Austria, 2013. Available at: http://wwwR-projectorg/ 2013.

84. Lausen B, Schumacher M. Maximally selected rank statistics. Biometrics 1992; 48: 85.

Cell Death and Disease is an open-access journal published by Nature Publishing Group. This work is

licensed under a Creative Commons Attribution 4.0 International License. The images or other third party material in this article are included in the article's Creative Commons license, unless indicated otherwise in the credit line; if the material is not included under the Creative Commons license, users will need to obtain permission from the license holder to reproduce the material. To view a copy of this license, visit http://creativecommons.org/licenses/by/4.0/

(C) The Author(s) 2017

Supplementary Information accompanies this paper on Cell Death and Disease website (http://www.nature.com/cddis) 